\title{
Self-supported porous Cobalt Oxide Nanowires with enhanced Electrocatalytic performance toward Oxygen evolution reaction
}

\author{
HAN XIA $^{\mathrm{a}, \mathrm{b}}$, ZHEN PENG $^{\mathrm{a}, *}$, CUNCAI L V $^{\mathrm{b}}$, YAOXING ZHAO ${ }^{\mathrm{b}}$, JINHUI HAO $^{\mathrm{b}}$ \\ and ZHIPENG HUANG ${ }^{\text {,** }}$

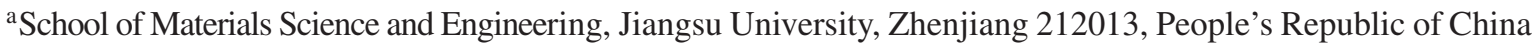 \\ ${ }^{\mathrm{b}}$ Functional Molecular Materials Research Centre, Scientific Research Academy, Jiangsu University, \\ Zhenjiang 212013, P. R. China \\ e-mail: peng@ujs.edu.cn; zphuang@ujs.edu.cn
}

MS received 5 July 2016; revised 11 September 2016; accepted 4 October 2016

\begin{abstract}
Development of hybrid electrocatalysts with high activity and good stability is crucial for oxygen evolution reaction (OER) of water electrocatalysis. In this work, cobalt oxide $\left(\mathrm{Co}_{3} \mathrm{O}_{4}\right)$ nanowires loaded on carbon fiber paper (CFP) were synthesized via hydrothermal method and annealing. The as-synthesized $\mathrm{Co}_{3} \mathrm{O}_{4}$ nanowires exhibit an enhanced catalytic activity with low onset overpotential (1.52 V vs. RHE) and a small overpotential of $330 \mathrm{mV}$ for a current density of $10 \mathrm{~mA} \mathrm{~cm}^{-2}$ with a Tafel slope of $60 \mathrm{mV} \cdot \mathrm{dec}^{-1}$. In addition, the $\mathrm{Co}_{3} \mathrm{O}_{4}$ nanowires maintain its electrocatalytic activity for at least $24 \mathrm{~h}$ in basic media. The enhanced performance of $\mathrm{Co}_{3} \mathrm{O}_{4}$ nanowires/CFP can be attributed to the high conductivity of CFP, the synergistic effect of $\mathrm{Co}_{3} \mathrm{O}_{4}$ and carbon, and high porosity of the nanowire. This study will open new possibilities for exploring water electrocatalysis.
\end{abstract}

Keywords. Electrocatalyst; oxygen evolution reaction; $\mathrm{Co}_{3} \mathrm{O}_{4}$ nanowires; carbon fiber paper; over potential.

\section{Introduction}

With the increase in population and the rapid socioeconomic development, energy requirements become more intensive. ${ }^{1-4}$ The conventional fossil fuels belong to non-renewable energy, and they emit plenty of harmful gases. ${ }^{1}$ The exploitation of sustainable and environmental energy is highly desirable., ${ }^{2,3}$ Electricity-driven water splitting is a promising way to solve the energy problem, having attracted already a broad interest. ${ }^{5,6}$

Water electrolysis can be divided into two half reactions: hydrogen evolution reaction (HER) and oxygen evolution reaction (OER). ${ }^{7}$ The OER is a 4-electron process to form only one oxygen molecule. ${ }^{8}$ Because the OER needs a larger overpotential to complete electrical catalysis process, the sluggish kinetics of the OER becomes a major limitation in efficient water electrolysis. ${ }^{7-10}$ Based on this, a lot of research has been focused on preparing low cost OER catalyst with high efficiency, and long-term stability. ${ }^{11}$ The main aim is to reduce the OER overpotential. Among many reported metal oxides, $\mathrm{RuO}_{2}, \mathrm{IrO}_{2}$, and $\mathrm{PtO}_{2}$ are regarded as the most active OER electrocatalysts, their scarcity and

\footnotetext{
*For correspondence
}

high cost greatly limit their large scale applications. ${ }^{12,13}$ Thus, there is considerable interest in developing OER catalysts based on earth-abundant metals such as Co, $\mathrm{Fe}$ and $\mathrm{Ni}$, the oxides of which exhibit efficient electrochemical activity in the OER. ${ }^{3,11,14}$ Currently, these non-noble transition-metal-based OER catalysts are usually obtained from precursor solutions of metal ions, and prepared as a thin films on two-dimensional planar substrates by common methods such as electrodeposition, dip-coating, sputtering, etc. ${ }^{3,15}$ Although performance has improved significantly, the structural, mechanical and electrical contact between catalyst and substrates should be optimized to further strengthen the stability and activity of the catalyst layer. ${ }^{3,6,10,11}$

Fabricating an ideal structure of catalysts is a direct and efficient approach to further optimize the OER performance. ${ }^{16}$ It has been demonstrated that a vertically aligned nanowire array of active components grown directly on current collectors can be considered as a new kind of highly effective electrodes. ${ }^{17}$ Definitely, this type of structure provides a tight coupling between catalyst and current collector and a short electron transport pathway, facilitating electron transport and electrolyte diffusion. Moreover, nanowire array significantly promotes the escape of as-formed gas 
bubbles from the surface of electrode, offering a stable and fast current increase. ${ }^{3,16,17}$ It is well-known that this structure was widely used for HER. Nevertheless, the application of nanowire array as an electrocatalyst for the OER has been rarely documented. ${ }^{13}$

In this work, we demonstrated the construction of $\mathrm{Co}_{3} \mathrm{O}_{4}$ nanowires $\left(\mathrm{Co}_{3} \mathrm{O}_{4} \mathrm{NW}\right)$ on carbon fiber paper (CFP) and its prominent electrocatalytic activity in the OER. The CFP- $\mathrm{Co}_{3} \mathrm{O}_{4} \mathrm{NW}$ has an onset potential of $1.52 \mathrm{~V}$ vs. reversible hydrogen electrode (RHE) and a fast current increase, affording a current density of $10 \mathrm{~mA} \mathrm{~cm}$ cm $^{-2}$ with overpotential as small as $330 \mathrm{mV}$. The performance is superb compared to that of other nanostructures with similar composition, Co precursor nanowire $\left(\mathrm{Co}(\mathrm{OH})\left(\mathrm{CO}_{3}\right)_{0.5} \mathrm{NW}\right)$ and $\mathrm{Co}_{3} \mathrm{O}_{4}$ nanorod $\left(\mathrm{Co}_{3} \mathrm{O}_{4} \mathrm{NR}\right)$, and that of other transition metal oxides. Meanwhile, the $\mathrm{CFP}-\mathrm{Co}_{3} \mathrm{O}_{4} \mathrm{NW}$ showed prominent stability at a high reaction rate for a long time and faradaic efficiency of $92 \%$ during water oxidation. The facile synthesis and prominent performance render the CFP- $\mathrm{Co}_{3} \mathrm{O}_{4} \mathrm{NW}$ promising material for a wide range of applications.

\section{Experimental}

\subsection{Reagents}

Cobalt nitrate hexahydrate $\left(\mathrm{Co}\left(\mathrm{NO}_{3}\right)_{2} \cdot 6 \mathrm{H}_{2} \mathrm{O}, \mathrm{AR}\right)$ and urea $\left(\mathrm{CO}\left(\mathrm{NH}_{2}\right)_{2}, \mathrm{AR}\right)$ were purchased from Sinopharm Chemical Reagent Co., Ltd. Ammonium fluoride $\left(\mathrm{NH}_{4} \mathrm{~F}, \mathrm{GR}\right)$ was purchased from shanghai Aladdin Industrial Corporation. Commercial CFP was purchased from Shanghai Hesen. All the reagents were used as received without further purification. Deionized water (resistivity: $18.2 \mathrm{M} \Omega \mathrm{cm}$ ) was used throughout our experiments.

\subsection{Materials Synthesis}

CFP was cut into pieces of $2 \times 6 \mathrm{~cm}^{2}$ and then cleaned by sequential sonication in acetone, $\mathrm{H}_{2} \mathrm{SO}_{4}$ solution, and deionized water each for $10 \mathrm{~min}$ to form a clean and hydrophilic surface for the hydrothermal growth. $\mathrm{Co}\left(\mathrm{NO}_{3}\right)_{2} \cdot 6 \mathrm{H}_{2} \mathrm{O}(0.87 \mathrm{~g}), \mathrm{CO}\left(\mathrm{NH}_{2}\right)_{2}(0.90 \mathrm{~g})$ and $\mathrm{NH}_{4} \mathrm{~F}$ $(0.22 \mathrm{~g})$ were dissolved in $80 \mathrm{~mL}$ water. The solution was transferred to a $100 \mathrm{~mL}$ Teflon-lined stainless steel autoclave loaded with a piece of CFP. The autoclave was then put in a constant temperature oven at $120^{\circ} \mathrm{C}$ for $7 \mathrm{~h}$. After cooling down to room temperature, the sample was taken out and washed ultrasonically with water several times. Finally the sample was dried at $80^{\circ} \mathrm{C}$ for 2 h. ${ }^{18,19}$
The pink $\mathrm{Co}(\mathrm{OH})\left(\mathrm{CO}_{3}\right)_{0.5} \mathrm{NW}$ samples were annealed at $250^{\circ} \mathrm{C}$ in air for $2 \mathrm{~h}$ with a ramping rate of $2^{\circ} \mathrm{C} \mathrm{min}{ }^{-1}$. After cooling down to room temperature, the ash black $\mathrm{Co}_{3} \mathrm{O}_{4}$ was formed on CFP. ${ }^{16,20}$

$\mathrm{Co}_{3} \mathrm{O}_{4}$ nanorods were prepared by annealing the $\mathrm{Co}(\mathrm{OH})\left(\mathrm{CO}_{3}\right)_{0.5}$ powder collected after hydrothermal growth at $250^{\circ} \mathrm{C}$ in air for $2 \mathrm{~h}^{20,21}$

Preparation of $\mathrm{Co}_{3} \mathrm{O}_{4}$ nanorod-loaded electrodes: $6 \mathrm{mg} \mathrm{Co} \mathrm{O}_{4}$ nanorod and $40 \mu \mathrm{L} 5 \mathrm{wt}$.\% Nafion solution were dispersed in $500 \mu \mathrm{L}$ water/ethanol $(\mathrm{v}: \mathrm{v}=4: 1)$ by 60 min sonication to form a catalyst ink. Then $45 \mu \mathrm{L}$ catalyst ink was loaded on CFP with a loading mass of $1.35 \mathrm{mg} \mathrm{cm}^{-2}$.

\subsection{Characterization}

The samples were characterized by X-ray diffraction (XRD, RIGAKU D/Max-2550 with $\mathrm{Cu} \mathrm{K \alpha}$ radiation), scanning electron microscopy (SEM, FEI SIRION), and transmission electron microscopy (TEM, JEOLJEM2010F).

\subsection{Electrochemical Measurements}

The electrochemical measurements were carried out by an electrochemistry workstation (CHI 614D) in a threeelectrode cell containing aqueous $\mathrm{KOH}$ solution $(1 \mathrm{M})$. The catalyst loaded on CFP was used as the working electrode, a mercury/mercury oxide electrode (MOE) as the reference electrode, and a high-surface-area $\mathrm{Pt}$ mesh as the counter electrode. A porous glass frit separated the chambers of working electrode and the counter electrode. The reversible hydrogen evolution potential (RHE) was determined by the open circuit potential of a clean Pt electrode in the solution of interest bubbled with $\mathrm{H}_{2}(99.999 \%)$. The potential measured vs. MOE was referenced to that versus RHE by adding $0.936 \mathrm{~V}$. The overpotential $(\eta)$ of OER was computed through $\eta$ $(\mathrm{V})=\mathrm{E}(\mathrm{RHE})-1.23 \mathrm{~V} \cdot{ }^{22}$

Linear sweep voltammetry (LSV) curves were measured at a scan rate of $5 \mathrm{mV} \cdot \mathrm{S}^{-1}$. The curves were corrected for the iR drop, where ' $\mathrm{I}$ ' is the current at relevant potential and $\mathrm{R}$ is the uncompensated cell resistance estimated by current-interrupt method. The Tafel slope was figured from the LSV curve by fitting experimental data to the equation $\eta=\mathrm{a}+\mathrm{b} \log \mathrm{j}$, where $\eta$ is iR-corrected potential, ' $a$ ' is Tafel constant, ' $b$ ' is Tafel slope, and ' $\mathrm{j}$ ' is current density. Electrochemistry impendence spectroscopy (EIS) were measured at $1.6 \mathrm{mV}$ vs. RHE in the frequency range of $10^{-2}$ to $10^{6} \mathrm{~Hz}$. The volume of $\mathrm{O}_{2}$ evolved during potentiostatic electrolysis experiment was monitored by water displacement method, and the details have been described in our previous publication. ${ }^{23}$ 


\section{Results and Discussion}

Figure 1 gives the scheme for the whole preparation process. The CFP was chosen here as the conductive substrate. Its relatively rough surface and high porosity structure may contribute to augment the active surface area. ${ }^{19}$ The synthesis of $\mathrm{Co}_{3} \mathrm{O}_{4} \mathrm{NWs}$ on CFP contains two steps: the synthesis of $\mathrm{Co}(\mathrm{OH})\left(\mathrm{CO}_{3}\right)_{0.5} \mathrm{NWs}$ on CFP using a hydrothermal method, and the annealing of the above sample in air. By the hydrothermal process, $\mathrm{Co}(\mathrm{OH})\left(\mathrm{CO}_{3}\right)_{0.5}$ NWs were successfully grown on CFP, and reliable contacts were formed between the NWs and CFP. ${ }^{19}$ After annealing, $\mathrm{Co}(\mathrm{OH})\left(\mathrm{CO}_{3}\right)_{0.5}$ was oxidized to $\mathrm{Co}_{3} \mathrm{O}_{4}$, and the morphology feature of self-supported nanowire array was still maintained. The $\mathrm{Co}_{3} \mathrm{O}_{4} \mathrm{NR}$ (not shown in the schematic) comes from cobalt carbonate hydroxide $\mathrm{Co}(\mathrm{OH})\left(\mathrm{CO}_{3}\right)_{0.5}$ collected from hydrothermal solution after heat-treatment.

The X-ray diffraction (XRD) pattern was recorded to determine the component of products. The XRD pattern of the sample resulted from hydrothermal growth is given in Figure 2a, and the pattern is matching well with that of the $\mathrm{Co}(\mathrm{OH})\left(\mathrm{CO}_{3}\right)_{0.5}$ (JCPDS PDF48-0058). ${ }^{19}$ Figure $2 \mathrm{~b}$ gives the XRD pattern of $\mathrm{Co}_{3} \mathrm{O}_{4}$ with different morphologies, including $\mathrm{Co}_{3} \mathrm{O}_{4} \mathrm{NWs}$ and $\mathrm{Co}_{3} \mathrm{O}_{4}$ NR. Both of them can be well-indexed to the cubic spinel $\mathrm{Co}_{3} \mathrm{O}_{4}$ (JCPDS 80-1534), and no detectable impurity phase could be found. It is therefore suggested that all precursors were successfully converted into
$\mathrm{Co}_{3} \mathrm{O}_{4}$. Owing to $\mathrm{Co}_{3} \mathrm{O}_{4}$ NWs and $\mathrm{Co}(\mathrm{OH})\left(\mathrm{CO}_{3}\right)_{0.5}$ NWs growth on the CFP, peaks corresponding to the CFP were labeled by rhomboids.

The morphologies of NWs of $\mathrm{Co}(\mathrm{OH})\left(\mathrm{CO}_{3}\right)_{0.5}$ and $\mathrm{Co}_{3} \mathrm{O}_{4}$ supported by $\mathrm{CFP}$ were examined with the scanning electron microscopy (SEM). As shown in Figures $3 \mathrm{a}$ and $3 \mathrm{~b}, \mathrm{Co}(\mathrm{OH})\left(\mathrm{CO}_{3}\right)_{0.5}$ NWs grew homogeneously on the surface of CFP. The diameter of the $\mathrm{Co}(\mathrm{OH})\left(\mathrm{CO}_{3}\right)_{0.5}$ nanowires is about $168 \mathrm{~nm}$ and their length is up to around $9.5 \mu \mathrm{m}$. After annealed at $250^{\circ} \mathrm{C}$ in air, the $\mathrm{Co}(\mathrm{OH})\left(\mathrm{CO}_{3}\right)_{0.5}$ NWs were completely converted into $\mathrm{Co}_{3} \mathrm{O}_{4}$ NWs without any morphology variation (Figures $2 \mathrm{c}$ and $2 \mathrm{~d}$ ). It was proved that annealing did not damage the shape of the structure. Nevertheless, the diameter of nanowires is decreased to $123 \mathrm{~nm}$. This may be attributed to gas (e.g., $\mathrm{CO}_{2}, \mathrm{H}_{2} \mathrm{O}$ ) escaping from the nanowire during the annealing process. ${ }^{10}$ Different magnification SEM of $\mathrm{Co}(\mathrm{OH})\left(\mathrm{CO}_{3}\right)_{0.5} \mathrm{NWs}$ and $\mathrm{Co}_{3} \mathrm{O}_{4}$ NWs were provided in Figure S1 (see Supplementary Information). The typical loading amount of the $\mathrm{Co}_{3} \mathrm{O}_{4} \mathrm{NWs}$ on the CFP was measured to be $1.35 \mathrm{mg} \mathrm{cm}^{-2}$. Figure $\mathrm{S} 2$ (Supplementary Information) shows a typical SEM image of $\mathrm{Co}_{3} \mathrm{O}_{4}$ NR. A rod-like morphology can be seen in the low magnification SEM image (Figure S2a, Supplementary Information), but the length is irregular. A high magnification SEM image (Figure S2b, Supplementary Information) shows that these nanorods have a rough surface.

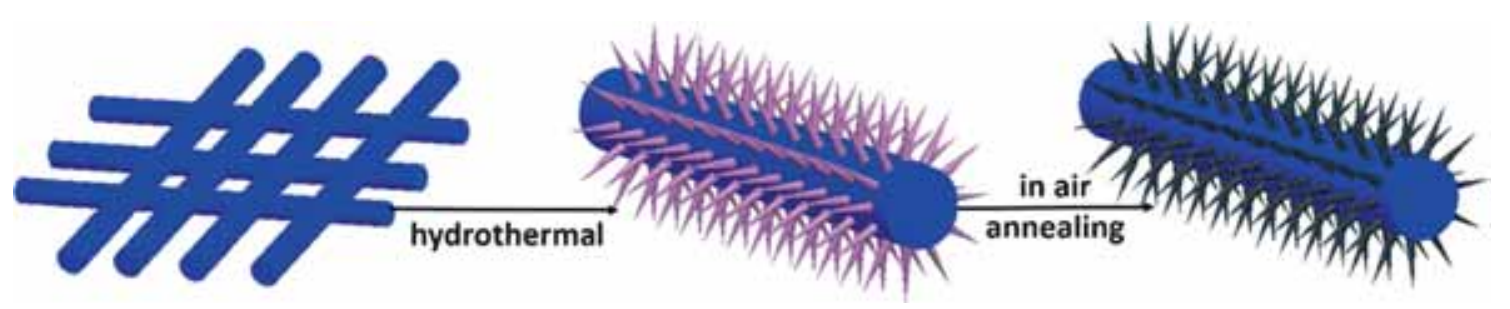

Figure 1. Schematic illustration of the synthesis of $\mathrm{Co}_{3} \mathrm{O}_{4} \mathrm{NWs}$ on CFP.
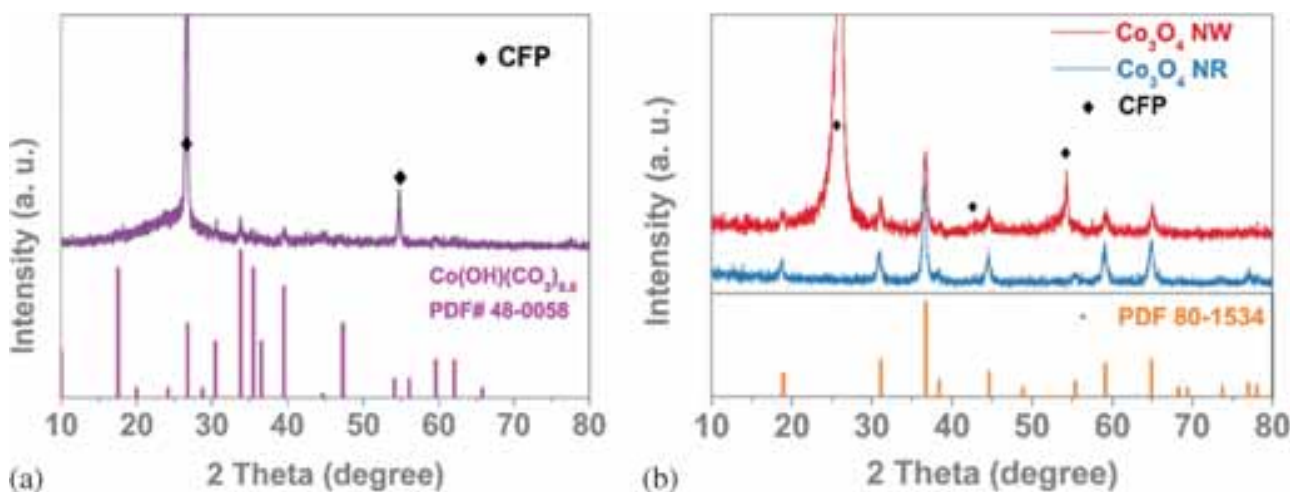

Figure 2. (a) XRD pattern of CFP- $\mathrm{Co}(\mathrm{OH})\left(\mathrm{CO}_{3}\right)_{0.5} \mathrm{NW}$. (b) XRD patterns of CFP-Co $\mathrm{O}_{4}$ $\mathrm{NW}$ (red line) and $\mathrm{Co}_{3} \mathrm{O}_{4} \mathrm{NR}$ (cyan line). 

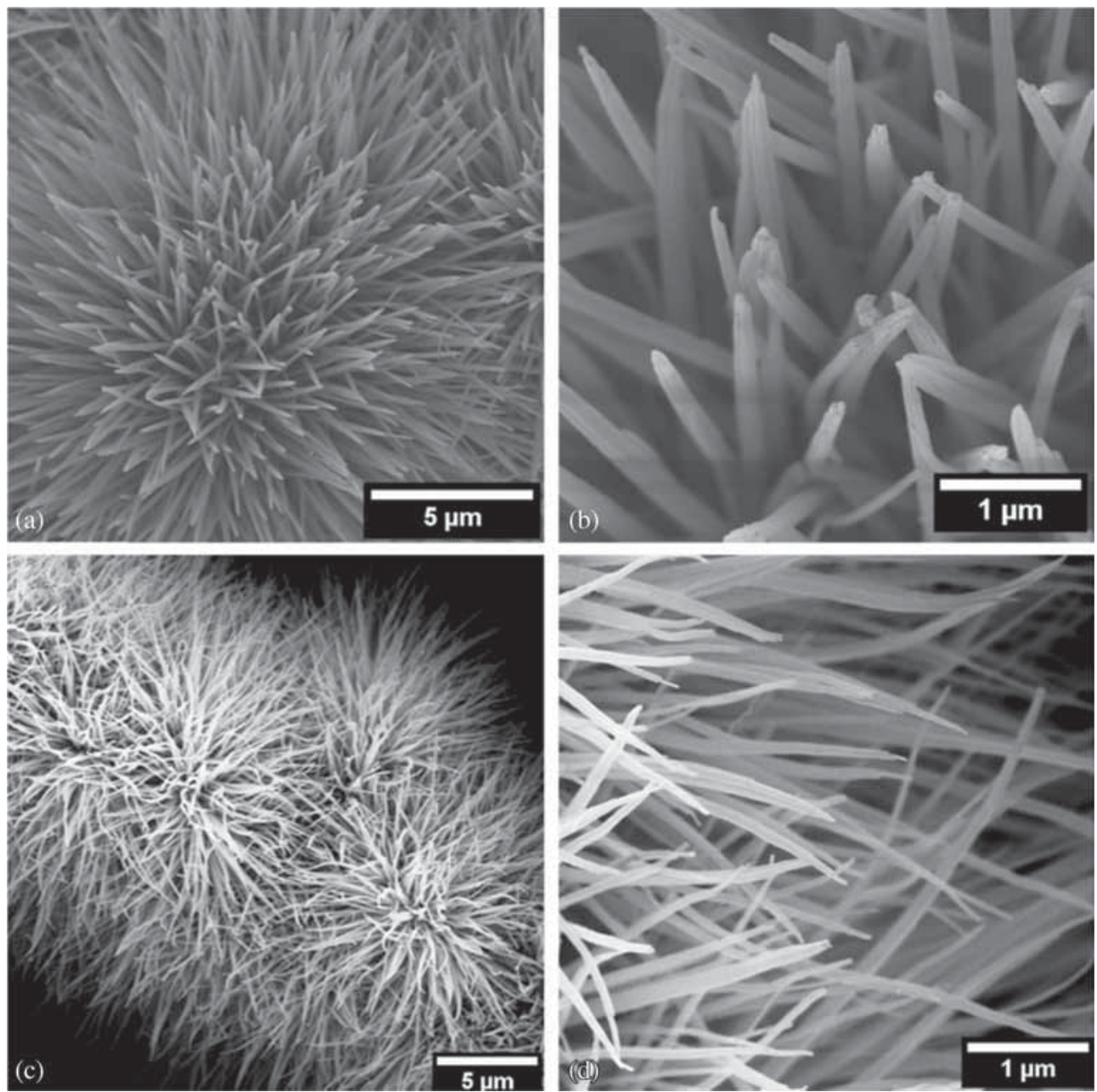

Figure 3. The SEM image of $\mathrm{Co}(\mathrm{OH})\left(\mathrm{CO}_{3}\right)_{0.5}$ on $\mathrm{CFP}\left((\mathrm{a})\right.$ and (b)) and $\mathrm{Co}_{3} \mathrm{O}_{4}$ nanowires $((\mathrm{c})$ and $(\mathrm{d}))$ array at a calcination ramping rate of $2^{\circ} \mathrm{C}$ per min.

The microstructure of $\mathrm{Co}_{3} \mathrm{O}_{4}$ nanowires was examined by TEM experiments (Figure 4). Figure 4a shows a low magnification TEM image of $\mathrm{Co}_{3} \mathrm{O}_{4}$ nanowires desquamated from the CFP substrate. The morphology of $\mathrm{Co}_{3} \mathrm{O}_{4}$ shown in the picture corresponds to that revealed by the SEM experiment. TEM image with larger magnification (Figure $4 \mathrm{~b}$ ) shows that the $\mathrm{Co}_{3} \mathrm{O}_{4}$ nanowires are composed of closely connected nanoparticles. The diameter of the nanoparticles is about $12.7 \mathrm{~nm}$. A lot of clearance formed between nanoparticles greatly enlarge the area of the interface. The high resolution TEM (HRTEM) image of a $\mathrm{Co}_{3} \mathrm{O}_{4}$ nanowire is given in Figure 4c. It is illustrated that the $\mathrm{Co}_{3} \mathrm{O}_{4}$ nanowire is poly-crystalline. The obvious lattice fringe can be found in its corresponding fast Fourier transform (FFT) pattern which is shown in the inset of Figure 4c. The pattern can be indexed to the $\left[\begin{array}{ll}1 & \overline{3} 0\end{array}\right]$ zone axis diffraction pattern of cubic phase $\mathrm{Co}_{3} \mathrm{O}_{4}\left(1 / \mathrm{d}_{\mathrm{OA}},=\mathrm{d}_{(31-1)}=0.24\right.$ $\mathrm{nm}, 1 / \mathrm{d}_{\mathrm{OB}}=\mathrm{d}_{(311)}=0.24 \mathrm{~nm}, 1 / \mathrm{d}_{\mathrm{OC}}=\mathrm{d}_{(002)}=0.41 \mathrm{~nm}$, $\angle \mathrm{AOB}=35.1^{\circ}$, and $\angle \mathrm{BOC}=72.4^{\circ}$ ).
To demonstrate the activity of Co for OER, the polarization curves was measured (Figure 5). The catalytic activity of the $\mathrm{Co}(\mathrm{OH})\left(\mathrm{CO}_{3}\right)_{0.5} \mathrm{NWs}$ grown on CFP electrodes was studied initially by linear sweep voltammetry (LSV) in a standard three-electrode cell. The overpotential required for a current density of $10 \mathrm{~mA} \mathrm{~cm}^{-2}\left(\eta_{10}\right)$ is $355 \mathrm{mV}$ for $\mathrm{Co}(\mathrm{OH})\left(\mathrm{CO}_{3}\right)_{0.5} \mathrm{NW}$. When it was completely converted to $\mathrm{Co}_{3} \mathrm{O}_{4} \mathrm{NW}$, the overpotential decreased to $330 \mathrm{mV}$. The OER activity ofCo $_{3} \mathrm{O}_{4} \mathrm{NR}$ deposited on CFP was examined with the same mass loading as that of $\mathrm{CFP}-\mathrm{Co}_{3} \mathrm{O}_{4} \mathrm{NW}$. It required an overpotential of $370 \mathrm{mV}$ to achieve the current density of $10 \mathrm{~mA} \mathrm{~cm}^{-2}$. Meanwhile, the CFP$\mathrm{Co}_{3} \mathrm{O}_{4} \mathrm{NW}$ had a low onsetpotential at $1.52 \mathrm{~V}$ vs. RHE. The small oxidative peak between 1.4 and $1.5 \mathrm{~V}$ vs. RHE is associated with the formation of $\mathrm{CoOOH} .{ }^{24-27}$ It is worth mentioning that lowering of overpotential to $330 \mathrm{mV}$ is needed to afford benchmark current density of $10 \mathrm{~mA} \mathrm{~cm}^{-2}$; it is superior to previous reports such as Ni-doped $\mathrm{Co}_{3} \mathrm{O}_{4}(530 \mathrm{mV})^{16}, \mathrm{Au} @ \mathrm{Co}_{3} \mathrm{O}_{4}(386 \mathrm{mV})^{28}$, $\mathrm{NiCo} \mathrm{LDH}(367 \mathrm{mV})^{29}$ and Co-P $(345 \mathrm{mV})^{30}$, and so on. 

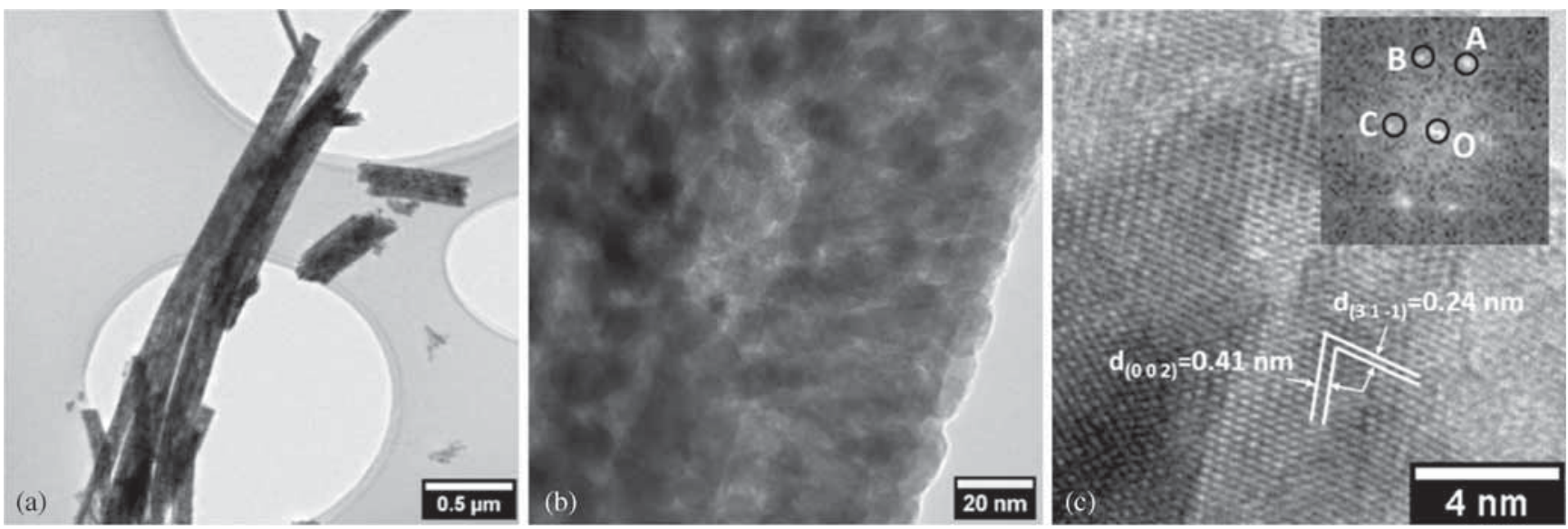

Figure 4. ((a) and (b)) TEM images of $\mathrm{Co}_{3} \mathrm{O}_{4}$ NW. (c) HRTEM image of $\mathrm{Co}_{3} \mathrm{O}_{4}$ NW. The inset is the FFT pattern of the lattice.
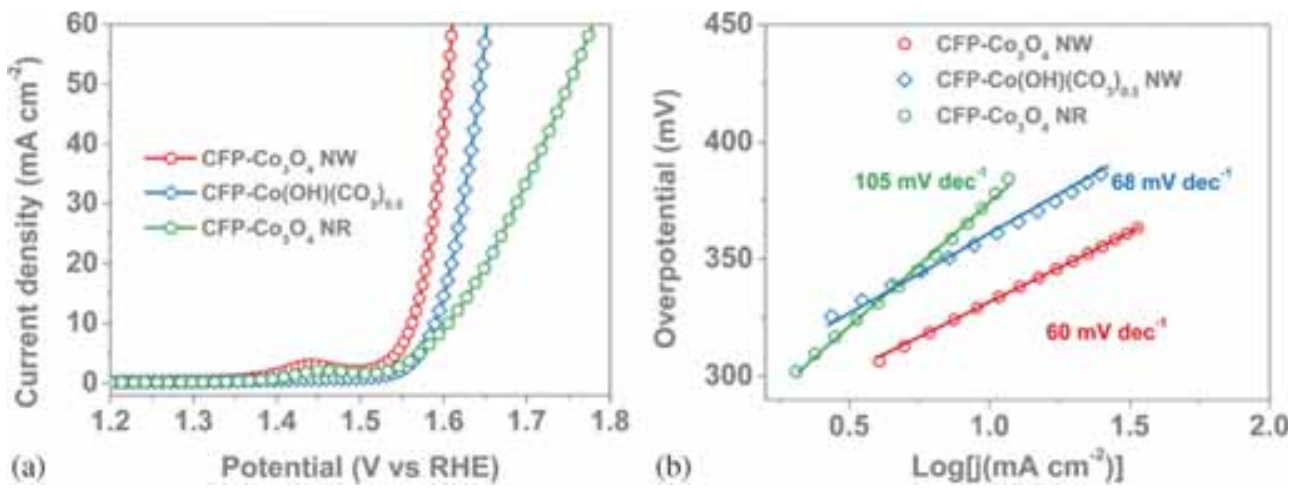

Figure 5. (a) Polarization curves of the $\mathrm{Co}(\mathrm{OH})\left(\mathrm{CO}_{3}\right)_{0.5} \mathrm{NW} @ \mathrm{CFP}$ (green line), $\mathrm{Co}_{3} \mathrm{O}_{4}$ NW@CFP (red line) and $\mathrm{Co}_{3} \mathrm{O}_{4}$ NR@CFP (cyan line). (b) Tafel plots of samples (red line: $\mathrm{Co}_{3} \mathrm{O}_{4}$ NW@CFP, green line: $\mathrm{Co}(\mathrm{OH})\left(\mathrm{CO}_{3}\right)_{0.5} \mathrm{NW} @ \mathrm{CFP}$, cyan line: $\left.\mathrm{Co}_{3} \mathrm{O}_{4} \mathrm{NR} @ \mathrm{CFP}\right)$.

A list of performance of various non-precious metal oxides in the OER can be found in Table S1 (Supplementary Information). To gain more insight on the OER activity, Tafel plots derived from polarization curves were constructed (Figure 5b). The resulting Tafel slope of $\mathrm{CFP}-\mathrm{Co}_{3} \mathrm{O}_{4} \mathrm{NW}$ was $60 \mathrm{mV} \cdot \mathrm{dec}^{-1}$, which is smaller than that of CFP-Co $(\mathrm{OH})\left(\mathrm{CO}_{3}\right)_{0.5} \mathrm{NW}\left(68 \mathrm{mV} \cdot \mathrm{dec}^{-1}\right)$ and $\mathrm{CFP}-\mathrm{Co}_{3} \mathrm{O}_{4} \mathrm{NR}\left(105 \mathrm{mV} \cdot \mathrm{dec}^{-1}\right)$, indicating that the CFP- $\mathrm{Co}_{3} \mathrm{O}_{4} \mathrm{NW}$ exhibited better OER activity. ${ }^{13}$

Electrochemically active surface area (ECSA) should play an important role in the high electrocatalytic performance, and it was derived from the specific capacitance measured by CV scans (Figure S3 in Supplementary Information). ${ }^{31}$ The potential range of the $\mathrm{CV}$ scans was selected at 1.1-1.2 V vs. RHE which did not include obvious electrochemical features corresponding to faradaic current. As a result, the dependence of the current on the scan rate in this region for both electrodes was linear, which was consistent with capacitive charging behavior. ${ }^{32}$ The specific capacitance of the CFP- $\mathrm{Co}_{3} \mathrm{O}_{4} \mathrm{NW}$, CFP-Co( $\left.\mathrm{OH}\right)\left(\mathrm{CO}_{3}\right)_{0.5} \mathrm{NW}$ and
CFP- $\mathrm{Co}_{3} \mathrm{O}_{4}$ NR were measured to be $39.6,34.6$ and $10.9 \mathrm{mF} \cdot \mathrm{cm}^{-2}$, respectively (Figure $\mathrm{S} 3 \mathrm{~d}$ ), and the corresponding ECSA is $990.0,865.0$, and $272.5 \mathrm{~cm}_{\mathrm{ECSA}}^{2}$ (detailed discussion is given in Supplementary Information), suggesting that the ECSA of the nanowire is much larger than that of the $\mathrm{CFP}-\mathrm{Co}_{3} \mathrm{O}_{4} \mathrm{NR}$. It is demonstrated that the nanowire structure could increase the number of electrochemically active sites for the OER. ${ }^{33,34}$

To further understand the surface area of the catalyst, the Brunauer-Emmett-Teller (BET) experiment was conducted. From BET measurements, the specific surface area of $\mathrm{Co}_{3} \mathrm{O}_{4} \mathrm{NW}$ was estimated as $34.644 \mathrm{~m}^{2} \mathrm{~g}^{-1}$, which is relatively larger than $\mathrm{Co}_{3} \mathrm{O}_{4} \mathrm{NR}\left(31.886 \mathrm{~m}^{2} \mathrm{~g}^{-1}\right)$. The nitrogen adsorption-desorption isotherm is shown in Figure S4 (Supplementary Information). The BET of $\mathrm{Co}_{3} \mathrm{O}_{4} \mathrm{NR}$ and $\mathrm{Co}_{3} \mathrm{O}_{4} \mathrm{NW}$ have slight differences but the ECSA of CFP- $\mathrm{Co}_{3} \mathrm{O}_{4} \mathrm{NR}$ is much smaller than that of CFP- $\mathrm{Co}_{3} \mathrm{O}_{4} \mathrm{NW}$. The smaller ECSA of CFP$\mathrm{Co}_{3} \mathrm{O}_{4} \mathrm{NR}$ correlates with its larger electron transport resistance, in comparison with that of $\mathrm{CFP}-\mathrm{Co}_{3} \mathrm{O}_{4} \mathrm{NW}$. In this case, the electrons cannot be delivered to every 

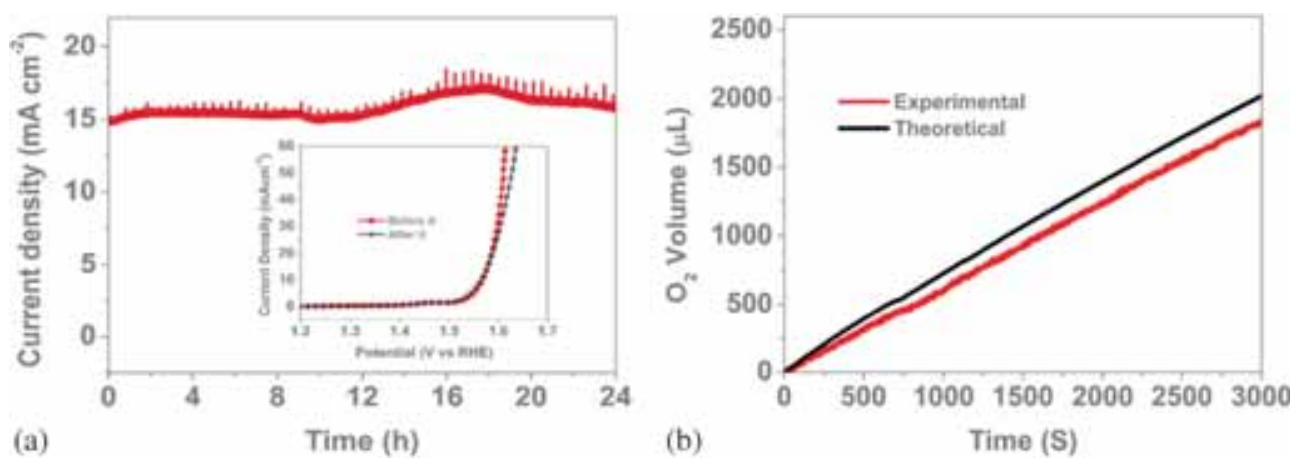

Figure 6. (a) The relationship of current density and time in a potentiostatic electrolysis experiment (applied potential: $1.57 \mathrm{~V}$ vs. RHE). The inset shows the LSV before and after electrolysis. (b) The comparison of theoretical and experimental volumes of the generated $\mathrm{O}_{2}$ in a potentiostatic electrolysis experiment (applied potential: $1.7 \mathrm{~V}$ vs. RHE, without iR correction).

$\mathrm{Co}_{3} \mathrm{O}_{4} \mathrm{NR}$, and some $\mathrm{Co}_{3} \mathrm{O}_{4} \mathrm{NR}$ will therefore be inert in HER. The BET and ECSA measurements demonstrate clearly that the growth of $\mathrm{Co}_{3} \mathrm{O}_{4} \mathrm{NW}$ directly on the surface of CFP is beneficial for the electron transport from electrode to catalyst and inside the catalyst, and is important to make every $\mathrm{Co}_{3} \mathrm{O}_{4} \mathrm{NW}$ active in the case of high catalyst loading.

High durability is important for the practical application of OER catalyst. ${ }^{35,36}$ Potentiostatic electrolysis was used to evaluate the stability of the $\mathrm{CFP}-\mathrm{Co}_{3} \mathrm{O}_{4}$ NW. No degradation of current density was found after $24 \mathrm{~h}$ of potentiostatic electrolysis (Figure 6a). However, the overpotential required to drive a current density of $60 \mathrm{~mA} \mathrm{~cm}^{-2}\left(\eta_{60}\right)$ increases from 370 to $400 \mathrm{mV}$ after the long time electrolysis test (the inset plot in Figure 6a). The decay of $\eta_{60}$ is about $8 \%$. The faradaic efficiency of the $\mathrm{Co}_{3} \mathrm{O}_{4} \mathrm{NW}$ during $\mathrm{O}_{2}$ evolution was evaluated by the comparison of the volume of generated gas and the theoretical volume in the potentiostatic electrolysis measurement. Before the test, the electrolyte was aerated $\left(\mathrm{O}_{2}\right)$ for $4 \mathrm{~h}$. The plots of theoretical and experimental volumes of the generated oxygen versus the experimental time are shown in Figure 6b. During electrolysis for $3000 \mathrm{~s}, 32$ coulombs of charge were passed and $1.86 \mathrm{~mL}$ of $\mathrm{O}_{2}$ was evolved, which gave a Faradaic yield of $92 \%$.

\section{Conclusions}

In summary, porous $\mathrm{Co}_{3} \mathrm{O}_{4}$ nanowire arrays were successfully grown on CFP through hydrothermal and calcination, and it exhibited superior OER activity compared to the CFP-Co(OH) $\left(\mathrm{CO}_{3}\right)_{0.5} \mathrm{NW}$ and CFP-Co $\mathrm{O}_{3}$ NR. The CFP- $\mathrm{Co}_{3} \mathrm{O}_{4} \mathrm{NW}$ has an onset potential of $10.52 \mathrm{~V}$ vs. RHE and only a small overpotential of $330 \mathrm{mV}$ is needed to afford a benchmark current density $\left(\eta_{10}\right)$. Moreover, the electrode is stable for $24 \mathrm{~h}$ at high current density and $92 \%$ faradaic efficiency. The porous three-dimensional architecture should play an essential role in enhancing the OER activity. It can offer an even higher surface area, while the conductivity can be well preserved.

\section{Supplementary Information (SI)}

Additional information about characterization of CFP$\mathrm{Co}(\mathrm{OH})\left(\mathrm{CO}_{3}\right)_{0.5}$ and $\mathrm{CO}_{3} \mathrm{O}_{4} \mathrm{NR}$ using SEM (Figures $\mathrm{S} 1$, $\mathrm{S} 2$ ), performance of representative electrocatalysts for water oxidation (Table S1), equivalent circuit used to fit the EIS data (Figure S3), values of elements in the equivalent circuit (Table S2), cyclic voltammograms (Figures S4), and calculation of electrochemical active surface area are given in the supporting information. Supplementary Information is available at www.ias.ac. in/chemsci.

\section{Acknowledgements}

This study was financially supported by the National Natural Science Foundation of China (61006049), Jiangsu Province (2011-XCL-019 and 2013-479), the Natural Science Foundation of Jiangsu (BK20131252), Natural Science Fund for Colleges and Universities in Jiangsu Province (Grant No. 16KJB430005) and Ordinary University Graduate Student Research Innovation Projects of Jiangsu Province (SJLX15_0487).

\section{References}

1. Chow J 2003 Sci. 3021528

2. Cook T R, Dogutan D K, Reece S Y, Surendranath Y, Teets T S and Nocera D G 2010 Chem. Rev. 1106474

3. Xu W W, Lu Z Y, Lei X D, Li Y P and Sun X M 2014 Phys. Chem. Chem. Phys. 1620402 
4. Wang J, Zhong H X, Wang Z L, Meng F L and Zhang X B 2016 ACS Nano 102342

5. Walter M G, Warren E L, McKone J R, Boettcher S W, Xi M Q, Santori E A and Lewis N S 2010 Chem. Rev. 1106446

6. Wang J, Zhong H X, Qin Y L and Zhang X B 2013 Angew. Chem. Int. Ed. Engl. 525248

7. McCrory C C, Jung S, Ferrer I M, Chatman S M, Peters J C and Jaramillo T F 2015 J. Am. Chem. Soc. 1374347

8. Markoulaki I V, Papadas I T, Kornarakis I and Armatas G 2015 Nanomaterials 51971

9. Long X, Li J, Xiao S, Yan K, Wang Z, Chen H and Yang S 2014 Angew. Chem. Int. Ed. 537584

10. Sharifi T, Gracia-Espino E, Jia X, Sandström R and Wågberg T 2015 ACS Appl. Mater. Interfaces 728148

11. Zou X X, Silva R, Goswami A, Sathe B and Asef T 2013 Chem. Commun. 497522

12. Koza J A, He Z, Miller A S and Switzer J A 2012 Chem. Mater. 243567

13. Chen R, Wang H Y, Miao J W, Yang H B and Liu B 2015 Nano Energy 11333

14. Yu X, Zhang M, Yuan W and Shi G 2015 J. Mater. Chem. A 36921

15. Wang H F, Tang C, Zhu X and Zhang Q 2016 J. Mater. Chem. A 43379

16. Lu B, Cao D, Wang P, Wang G and Gao Y 2011 Int. J. Hydrogen Energy 3672

17. Ma T Y, Dai S, Jaroniec M and Qiao S Z 2014 J. Am. Chem. Soc. 13613925

18. Faber M S, Dziedzic R, Lukowski M A, Kaiser N S, Ding Q and Jin S 2014 J. Am. Chem. Soc. 13610053

19. Wang K, Zhou C J, Xi D, Shi Z Q, He C, Xia H Y, Liu G W and Qiao G J 2015 Nano Energy 181

20. Rakhi R B, Chen W, Hedhili M N, Cha D and Alshareef H N 2014 ACS Appl. Mater. Interfaces 64196
21. Zhou X, Shen X, Xia Z, Zhang Z, Li J, Ma Y and Qu Y 2015 ACS Appl. Mater. Interfaces 720322

22. Liu T, Liang Y, Liu Q, Sun X, He Y and Asiri A M 2015 Electrochem. Commun. 6092

23. Huang Z P, Chen Z Z, Chen Z B, Lv C C, Humphrey M G and Zhang C 2014 Nano Energy 9373

24. Sayeed M A, Herd T and O' Mullane A P 2016 J. Mater. Chem. A 4991

25. Tahir M, Mahmood N, Zhang X, Mahmood T, Butt F K, Aslam I, Tanveer M, Idrees F, Khalid S, Shakir I, Yan Y, Zou J, Cao C and Hou Y 2015 Nano Res. 83725

26. Wu L, Li Q, Wu C H, Zhu H, Mendoza-Garcia A, Shen B and Guo J 2015 J. Am. Chem. Soc. 1377071

27. Mao S, Wen Z, Huang T, Hou Y and Chen J 2014 Energy Environ. Sci. 7609

28. Zhuang Z, Sheng W and Yan Y 2014 Adv. Mater. 263950

29. Liang H, Meng F, Caban-Acevedo M, Li L, Forticaux A, Xiu L, Wang Z and Jin S 2015 Nano Lett. 151421

30. Jiang N, You B, Sheng M and Sun Y 2015 Angew. Chem. Int. Ed. Engl. 546251

31. Song F and Hu X 2014 Nat. Commun. 51

32. Kibsgaard J and Jaramillo T F 2014 Angew. Chem. Int. Ed. Engl. 5314433

33. Zhao Y F, Chen S Q, Sun B, Su D W, Huang X D, Liu $\mathrm{H}$, Yan Y M, Sun K N and Wang G X 2015 SCI REP-UK 76291

34. Yan X D, Li K X, Lyu L, Song F, He J, Niu D, Liu L, $\mathrm{Hu}$ X and Chen X B 2016 ACS Appl. Mater. Interfaces 83028

35. Zhang X L, Zhang J B and Wang K 2015 ACS Appl. Mater. Interfaces 720745

36. Hu H, Guan B Y, Xia B Y and Lou X W 2015 J. Am. Chem. Soc. 1375590 